\title{
Las músicas migrantes latinoamericanas en Chile: identidades diaspóricas y mestizajes culturales ${ }^{*}$
}

\author{
Marisol Facuse Muñoz \\ Rodrigo Torres Alvarado**
}

Recibido: 5 de enero de 2018

Evaluado: 25 de enero 2018

Aceptado: 16 de abril de 2018

\section{Resumen}

Desde el período de posdictadura en Chile, la llegada de comunidades latinoamericanas ha generado una progresiva transformación en el patrón migratorio. En este contexto, la investigación que aquí presentamos se propuso comprender la incidencia de la producción cultural de los inmigrantes en nuestras identidades, sociabilidades e imaginarios. En particular, nos hemos interesado en las prácticas musicales sosteniendo que la música fomenta procesos de mestizaje cultural, provocando una transformación y una reconfiguración de las identidades. Metodológicamente, el estudio se basó en el enfoque etnográfico y en entrevistas comprensivas a artistas de diversos géneros musicales. Los resultados revelan la existencia de distintos tipos de identidades, las que se declinan y combinan a partir de pertenencias nacionales, étnicas, religiosas o profesionales. Concluimos con ello que las nuevas inmigraciones han repercutido de manera importante en las dinámicas culturales actuales, suscitando vínculos sociales y mestizajes entre comunidades más allá de las fronteras nacionales y simbólicas.

Palabras clave: migraciones en América Latina, músicas migrantes, mestizajes culturales, identidades diaspóricas.

\footnotetext{
Artículo de investigación. Los resultados expuestos se insertan en el marco de una investigación de tres años de duración llevada a cabo en el marco del Proyecto Fondecyt № 110928 titulado: "El mundo de las músicas inmigrantes latinoamericanas en Chile: identidades, sociabilidades y mestizajes culturales", coordinado por los autores y realizado con el apoyo de los tesistas de pre y posgrado María Ignacia Villagra, Malén Cayupi, Constanza Lobos, Daniela Forné, Francisca Cornejo, Ana Cubides, Pablo Albornoz y el realizador audiovisual Jorge Leiva. DOI: http://dx.doi. org/10.15332/ s1794-3841.2018.0029.05

** Doctora en Sociología del Arte y la Cultura. Profesora asociada, Universidad de Chile. Correo electrónico: marisolfacuse@uchile.cl. Dirección postal: Universidad de Chile, Facultad de Ciencias Sociales, Departamento de Sociología, Avenida Capitán Ignacio Carrera Pinto No 1045 Nuñ̃oa, Santiago de Chile.

** DEA en Etnomusicología. Profesor asociado, Universidad de Chile. Correo electrónico: rtorres@uchile.cl. Dirección postal: Universidad de Chile, Facultad de Artes, Departamento de Música y Sonología, Compañía № 1264, Santiago de Chile.
} 


\section{Latin American migrant musics in Chile: diasporic identities and cultural mixing}

\begin{abstract}
Since the post-dictatorial period in Chile, the arrival of Latin American communities has generated a steady transformation in the migration pattern. In this study we aim to understand the effect of the cultural creations of immigrants on our identities, sociabilities and imaginaries. In particular, we are interested in the musical practices, putting forward the idea that music involves processes of cultural mixing, creating a transformation and a reshaping of identities. Methodologically, the study is based on an etnographic focus and on comprehensive interviews with artists of various types of music. The results reveal the existence of distinct kinds of identities, which wane and combine involving elements of natonality, ethnicity, religion and profesional. We conclude from this that the new migratory movements have marked in an important way the present cultural dynamics, creating social links and mixing between communities well beyond national and symbolic bounderies.
\end{abstract}

Keywords: Latin America migrations, migrant musics, cultural mixing, diasporic identities.
Received: January 5, 2018

Evaluated: January 25, 2018

Accepted: April 16, 2018 


\section{Música migrante latino-americana no Chile: identidades diaspóricas e mestiçagens culturais}

Recebido: 5 de janeiro de 2018

Avaliado: 25 de janeiro de 2018 Aceito: 16 de abril de 2018

\section{Resumo}

Desde o período pós-ditadura no Chile, a chegada de comunidades latino-americanas gerou uma transformação progressiva no padrão migratório. Nesse contexto, a pesquisa aqui apresentada teve como objetivo compreender o impacto da produção cultural dos imigrantes sobre nossas identidades, sociabilidades e imaginários. Em particular, nos interessamos pelas práticas musicais, argumentando que a música promove processos de miscigenação cultural, provocando uma transformação e uma reconfiguração de identidades. Metodologicamente, o estudo baseou-se na abordagem etnográfica e em entrevistas abrangentes com artistas de diferentes gêneros musicais. Os resultados revelam a existência de diferentes tipos de identidades, aquelas que são declinadas e combinadas com base em pertences nacionais, étnicos, religiosos ou profissionais. Concluímos que os novos imigrantes tiveram um impacto importante na dinâmica cultural atual, promovendo laços sociais e cruzamentos entre comunidades além das fronteiras nacionais e simbólicas.

Palavras-chave: migrações na América Latina, música migrante, mestiçagens culturais, identidades diaspóricas. 


\section{INTRODUCCIÓN}

Este trabajo propone volver sobre la extensa discusión presente en las ciencias sociales acerca de los diálogos y los procesos de influencia mutua entre culturas, reconocidos a partir de conceptos como transculturación, hibridación o mestizaje cultural. De manera particular, nos hemos interesado por las transformaciones y la reconfiguración de las identidades que tienen lugar a partir de los encuentros y préstamos culturales surgidos como consecuencia de los actuales procesos migratorios en América Latina, conocidos como migraciones Sur-Sur.

Para ello, buscamos analizar las prácticas musicales de las comunidades inmigrantes latinoamericanas residentes en Chile y las interacciones que suscitan, asumiendo la música como un recurso particularmente eficaz que puede operar como mediadora entre experiencias pasadas y presentes, entre lugares de origen y los que se habitan en la actualidad. En este contexto, que algunos autores han reconocido como de globalización cultural (Burke, 2013), buscamos comprender cómo la música puede contribuir a fomentar el encuentro y el intercambio entre culturas diferentes, a través de la creación de nuevas dinámicas colectivas (Duvignaud, 1981).

De este modo, sostenemos como hipótesis que las prácticas musicales de los inmigrantes pueden fomentar la creación de vínculos sociales entre individuos y colectivos de distintos lugares de procedencia, siendo un terreno fecundo para los mestizajes culturales (Laplantine y Nouss, 2007 y 2008). Tomando este concepto como punto de partida, exploramos los cruces entre culturas, prácticas artísticas, trayectorias individuales, imaginarios sonoros, géneros y estilos musicales; todos componentes de lo que hemos reconocido como el mundo de las músicas inmigrantes latinoamericanas en Chile.

Consideramos que el aumento de la inmigración de latinoamericanos en la última década en nuestro país, ha hecho emerger un tipo particular de producción sociocultural en torno a la práctica musical. La existencia de estas músicas en el espacio urbano genera vínculos entre sujetos y colectivos, formados por inmigrantes y población nativa, a partir de los cuales se reconfiguran las identidades culturales de unos y otros. Con ello, buscamos responder a las preguntas generales de: ¿Cómo las músicas inmigrantes posibilitan procesos de mestizaje cultural? ¿Cómo intervienen en la reconfiguración de las identidades de individuos y colectivos? ¿Qué nuevas formas de sociabilidad se producen en torno a estas prácticas musicales? ¿Qué imaginarios vehiculan, recrean o hacen emerger?

Partiendo de una comprensión del fenómeno musical como un proceso social que va de la producción a la interpretación (Esquenazi, 2007), nos hemos propuesto comprender el mundo de las músicas inmigrantes latinoamericanas en Chile y su relación con los procesos de mestizaje cultural, la metamorfosis de las identidades, las sociabilidades y los imaginarios de las comunidades que les dan vida. Para ello, observamos diferentes experiencias en que se reúnen música e inmigración: festivales, encuentros, fiestas nacionales y ferias interculturales, entre otras. Además, realizamos 46 entrevistas a músicos de diferentes nacionalidades residentes en Chile, considerando sus trayectorias y las repercusiones 
de la experiencia diaspórica en su práctica musical. Asimismo, con el fin de comprender la organización social del trabajo artísti$\mathrm{co}$, analizamos las redes de cooperación, los actores y las instituciones que posibilitan el desarrollo y la difusión de estas músicas en Chile, utilizando el concepto de mundos del arte propuesto por Howard Becker (2008). Este trabajo se complementó con entrevistas a públicos asistentes a los eventos, reconociendo la importancia de los procesos de recepción y los vínculos que se generan a partir de la escucha musical, con lo que buscamos conocer los efectos sociales de la producción artística sobre los sujetos y colectividades que en torno a ella se congregan (Péquignot, 2007).

En el presente artículo profundizaremos en la cuestión de la reconfiguración de las identidades y los mestizajes culturales a partir de la narrativa de los músicos entrevistados, buscando comprender, ¿cómo influye la práctica musical en la experiencia diaspórica?, ¿puede la música constituirse como un vehículo de integración, de encuentro y de diálogo intercultural? Y recíprocamente, ¿cómo las prácticas musicales se van transformando a propósito de la experiencia migratoria?, ¿cómo pueden favorecer procesos de mestizaje musical y artístico? O bien, ¿cómo pueden fomentar procesos de reafirmación de las identidades nacionales, de repliegue sobre sí, en comunidades e individuos que se reinventan en un contexto nuevo?

\section{Música, SOCIOLOGía Y PROCESOS MIGRATORIOS}

La condición emergente de este mundo del arte permitió constatar que nos encontramos en un momento privilegiado para su estudio, pudiendo dar cuenta del surgimiento de nuevas dinámicas sociales, artísticas y culturales generadas por los procesos migratorios. En Chile, recientes investigaciones sociológicas han profundizado en distintos aspectos del fenómeno migratorio, abordando desde los procesos de racialización (Tijoux, 2016) hasta la lucha por el reconocimiento (Thayer, 2011), las cuestiones de género y familia (Stefoni, 2011; Stefoni y Bonhomme, 2015) y los vínculos con el país de origen (Márquez, 2014; Márquez y Correa, 2015). Asimismo, desde la sociología urbana se ha dado relevancia a la heterogeneidad y multiculturalidad que aportan los inmigrantes internacionales a la ciudad y al espacio público (Arriagada y Órdenes, 2011). Investigaciones más recientes han comenzado poco a poco a interesarse por las prácticas culturales de los inmigrantes de países vecinos residentes en Chile, abordando las prácticas festivas, religiosas $\mathrm{y}$ culinarias (Caba y Rojas, 2014; Imilan, 2014; Imilan y Millaleo, 2015). En el ámbito más específico de las relaciones entre música e inmigración en la era global, son importantes trabajos como el de Miguel Olmos (2012), quien toma como punto de partida el análisis de la comunicación musical para darle significación a los procesos de movilidad artística y readaptación de los músicos y sus músicas en el trayecto migrante.

Conscientes de la complejidad del fenómeno musical y de la necesidad de elaborar enfoques interdisciplinarios, hemos hecho converger aportes de la sociología y de la musicología para abordar esta problemática a fin de profundizar en las consecuencias sociales y culturales de la música en la vida colectiva. 


\section{Mestizajes, HibRidaciones Y TRANSCULTURACIÓN: CONTROVERSIAS Y QUERELLAS}

El título de este artículo deja entrever la proliferación de términos que han emergido en las ciencias sociales para dar cuenta del fenómeno del intercambio y de la mutua influencia entre culturas, pueblos o grupos sociales. Algunas más felices que otras, estas nociones han sido propuestas en contextos disciplinarios y teóricos diversos, siendo cada uno el objeto de críticas más o menos fundamentadas. Una de las más frecuentes pone el acento en la impronta biologicista de algunos de estos conceptos, muchos de ellos originados en las ciencias naturales -como es el caso de hibridismo y mestizaje-. A su vez, conceptos como el de aculturación o transculturación han sido puestos en tela de juicio por ser tributarios de una noción de la cultura entendida como un sistema totalizante que existiría con independencia de los individuos, una representación ampliamente discutida por la antropología y por la sociología.

En el contexto latinoamericano, se suman a esta controversia los usos políticos de que han sido objeto algunos de estos términos, en particular el de mestizaje, por tratarse de una clara metáfora racial trasladada a la cultura, exaltada por las élites dominantes que buscaron articular un discurso pacificador y unificador tras las guerras de independencia. La figura del mestizo se ha erigido a través de discursos literarios, culturales o políticos como una nueva síntesis homogénea que ha terminado por expulsar la diversidad étnica, cultural y social de nuestro continente, dejando fuera de los relatos nacionales al sujeto indígena y afrodescendiente $^{1}$.

Teniendo en cuenta el carácter controversial de este debate, nos hemos propuesto volver sobre la discusión acerca de las metamorfosis de las culturas y de los grupos sociales a partir de aquello que algunos autores han reconocido como una epistemología del mestizaje (Laplantine y Nouss, 2008; Amselle, 2010; Gruzinski, 2000), en la que se valoriza la mezcla por sobre el purismo, la heterogeneidad por sobre la homogeneidad, lo impermanente y fragmentario por sobre una idea de cultura comprendida como totalidad inmutable. Así entendido, el concepto de mestizaje cultural designa el proceso de mutua transformación entre culturas que se encuentran y se influencian recíprocamente gracias al paso del tiempo. Laplantine y Nouss (2007) refiriéndose a este proceso, señalan:

El mestizaje, lo contrario del autismo, es lo que nos arranca de la repetición de lo mismo, de la reproducción de lo compacto en un marco delimitado. No es lo que se encaja o se suelda. No se da en la constancia y la consistencia, sino

1 Este imaginario del mestizo fue nutrido por la literatura y la historia a través de autores emblemáticos como José Vasconcelos en México o Gilberto Freyre en Brasil. Con su concepto de "raza cósmica", Vasconcelos planteó la integración de los distintos grupos étnicos que han contribuido a formar la población americana, latinos y sajones incluidos, como solución para sus tensiones raciales y como fórmula que el continente podría ofrecer a la historia de la civilización. En una perspectiva similar, el historiador Gilberto Freyre sostuvo que, gracias al mestizaje, América Latina ha evitado los conflictos raciales característicos de las naciones segregacionistas, creando en algunos países "verdaderas democracias raciales" (Jaramillo, 2006, p. 39). 
que se elabora en el desfasaje y la alternancia. El mestizaje se reconoce por un movimiento de tensión, de vibración, de oscilación, que se manifiesta a través de formas transitorias que se reorganizan de otro modo (p. 25).

Para estos autores, la música parece constituir un dominio privilegiado para los mestizajes culturales, como lo evidencian a través de los ejemplos del bossa nova, el hip-hop y el jazz. De este modo, el concepto de mestizaje constituye una alternativa plausible frente a las nociones de sincretismo e hibridación para analizar las dimensiones socioculturales del fenómeno migratorio.

En el ámbito más específico de la globalización de la música, algunos autores han incorporado nuevos términos a esta discusión, como es el caso de Josep Martí (2004), quien propone hablar de "entramados culturales" para hacer referencia a un conjunto de significaciones compartidas por comunidades de diversa naturaleza, independiente de sus pertenencias nacionales, étnicas o de su arraigo a un territorio, más allá de nociones como la de transculturación o aculturación.

El concepto de mestizaje cultural ha tenido gran centralidad en nuestro dispositivo de investigación. A partir de él nos propusimos explorar el encuentro de culturas, formas musicales, biografías, instrumentos, tipos de escenificación, sonoridades e imaginarios. Con ello esperamos contribuir a la reflexión más general sobre el mestizaje, comprendido como una experiencia vital que expresa las numerosas influencias que han constituido la cultura latinoamericana.

\section{Dispositivo Metodológico Y TÉCNICAS DE PRODUCCIÓN DE INFORMACIÓN}

El dispositivo de investigación se basó en el método etnográfico (Geertz, 2000; Becker, 2009; Lapassade, 1996), mediante la observación directa de actividades artísticas y entrevistas comprensivas (Kaufmann, 2011) a músicos profesionales y aficionados que iniciaron sus carreras artísticas en sus países de origen ${ }^{2}$. Considerando los aportes de Tia DeNora (2004), estimamos que este método resulta adecuado para analizar los mundos musicales, ya que siguiendo a los actores y sus usos sociales concretos, es posible trazar las mediaciones que hay entre la música y lo social.

Las entrevistas se realizaron también a mediadores, técnicos y públicos iniciados o aficionados (Hennion, 2002), con el fin de comprender la red de relaciones y los vínculos particulares que estos actores establecen con las músicas inmigrantes. Entendimos por públicos iniciados a los individuos que tienen un conocimiento mayor de estas músicas, ya sea por su condición de inmigrantes o por su acercamiento a través de viajes o de su participación en agrupaciones, lo que los lleva a establecer una relación más permanente con estos circuitos. Para el tratamiento de entrevistas se utilizó un análisis temático (Silverman, 2011), apegado al discurso de los informantes, con lo cual se buscó hacer emerger los significados

2 Los diversos productos documentales y audiovisuales de esta investigación pueden ser consultados en el sitio web: www.musicasmigrantes.cl 
y categorías que los propios actores usan para estructurar sus percepciones acerca del mundo de las músicas inmigrantes (Cluley, 2012). Como complemento de la observación in situ y de las entrevistas, se consideró el material producido por los propios actores sobre su quehacer, teniendo en cuenta sus páginas de Facebook, videoclips, etc., con el objetivo de acceder a la autorrepresentación de los colectivos acerca de su actividad y del sentido que le otorgan.

La reconstitución de las trayectorias de los músicos y de los circuitos que se articulan en torno a sus actividades, nos permitieron profundizar en diferentes artistas de este particular mundo del arte, teniendo en cuenta aspectos artísticos, organizacionales, territoriales, socioculturales y biográficos. En las entrevistas se consideraron tanto a inmigrantes como a población nativa que participa de estas actividades musicales.

En el siguiente apartado, describiremos el contexto de las observaciones de terreno para luego, a partir de las trayectorias de artistas, dar cuenta de distintos tipos de identidad presentes en los músicos, tomando como eje del análisis los cruces entre música y experiencia migratoria.

\section{TERRENOS Y CASOS}

Los lugares de observación de nuestra investigación, fueron festividades nacionales, religiosas y barriales, llevadas a cabo en distintas comunas de la Región Metropolitana de Santiago, en donde la música, la danza y la gastronomía cobran gran relevancia (Tabla 1).

Tabla 1. Actividades de músicas inmigrantes que se realizan en la Región Metropolitana de Santiago

\begin{tabular}{lll}
\hline Actividad & Organizador & Comuna(s) \\
\hline Día del Refugiado & Municipalidad y otros & Quilicura \\
\hline Día Nacional del Migrante & $\begin{array}{l}\text { Instituto Católico Chileno de } \\
\text { Migración y Parroquia Italiana }\end{array}$ & Providencia \\
\hline Día Internacional del Inmigrante & $\begin{array}{l}\text { Intendencia, municipalidad y } \\
\text { otros }\end{array}$ & $\begin{array}{l}\text { Santiago, Providencia, Cerrillos } \\
\text { y Maipú }\end{array}$ \\
\hline Día Nacional del Perú & Municipalidades y otros & Recoleta, Santiago y Las Condes \\
\hline Día Nacional de Colombia & Municipalidad y otros & Providencia \\
\hline $\begin{array}{l}\text { Día Nacional de República } \\
\text { Dominicana }\end{array}$ & Parroquia Italiana & Providencia \\
\hline Feria Interculturalidad y Barrio & Municipalidad & Providencia \\
\hline $\begin{array}{l}\text { La Cumbiateka (espectácu- } \\
\text { lo cultural de integración } \\
\text { latinoamericana) }\end{array}$ & $\begin{array}{l}\text { Centro Cultural Estación } \\
\text { Mapocho }\end{array}$ & Santiago \\
\hline $\begin{array}{l}\text { Grupo musical Mákina Kandela } \\
\text { Grupo musical La Chicha y su }\end{array}$ & $\begin{array}{l}\text { Municipalidades, Sociedad } \\
\text { (SCD) y otros }\end{array}$ & $\begin{array}{l}\text { Santiago, Recoleta, Independen- } \\
\text { cia, Recoleta y Providencia }\end{array}$ \\
\hline
\end{tabular}

Fuente: elaboración propia. Bitácora de observaciones en terreno de investigadores del Proyecto Fondecyt Regular № 110928. 
Los promotores de estas actividades son por lo general agentes culturales locales (ONG, municipalidades, Iglesias, etc.), así como también las propias comunidades inmigrantes autoorganizadas. Los valores principales que se destacan en torno a estas escenas son la diversidad cultural, la multiculturalidad y la importancia para Chile de convertirse en un país de acogida de estos nuevos habitantes que vienen a aportar una mayor riqueza cultural. La música y la danza desempeñan un rol fundamental en estos encuentros, como formas privilegiadas para poner en escena estas culturas en un nuevo contexto. A partir de ellas, se crean espacios de interacción entre inmigrantes de distintas nacionalidades y población nativa, lo que nos aproxima a la reflexión más general en torno al lugar de la música en la generación de un vínculo social (Dutheil-Pessin, 2004) en el contexto migratorio.

El marco de esta investigación abordó principalmente a los músicos instalados en Chile a partir de la década de los noventa, así como también a otros integrantes de estas redes que hemos reconocido como los mundos del arte de la música inmigrante, tales como organizadores, personal técnico y públicos (Tabla 2).

Tabla 2. Músicos y mediadores entrevistados en la investigación

\begin{tabular}{|c|c|c|c|}
\hline $\begin{array}{l}\text { Nombre del } \\
\text { entrevistado }\end{array}$ & País de origen & $\begin{array}{l}\text { Actividad musical (oficio o grupos } \\
\text { musicales) }\end{array}$ & Género musical \\
\hline 1. Domingo Alicera & Chile & $\begin{array}{l}\text { Guitarrista. Escuelita Abierta para } \\
\text { Creadores y Libres y Conchalí Big } \\
\text { Band }\end{array}$ & Jazz \\
\hline 2. Héctor Villanueva & $\begin{array}{l}\text { República } \\
\text { Dominicana }\end{array}$ & $\begin{array}{l}\text { Cantante. Grupo Swing } \\
\text { Dominicano }\end{array}$ & Bachata \\
\hline $\begin{array}{l}\text { 3. Angélica } \\
\text { Altamirano }\end{array}$ & Perú & Cantante & Música criolla \\
\hline 4. Tino Alegría & Perú & $\begin{array}{l}\text { Cantante, guitarrista, percusionista. } \\
\text { Grupo Tres Sabores del Perú }\end{array}$ & $\begin{array}{l}\text { Música criolla, afrope- } \\
\text { ruana y bolero }\end{array}$ \\
\hline 5. Martín Zegarra & Perú & Percusionista, cantante y bailarín & $\begin{array}{l}\text { Música criolla, afrope- } \\
\text { ruana, salsa, bolero y } \\
\text { cueca }\end{array}$ \\
\hline 6. Gisella Plaza & Ecuador & Cantante & $\begin{array}{l}\text { Tecnocumbia, salsa y } \\
\text { balada }\end{array}$ \\
\hline 7. William Bonilla & Colombia & Presidente Asociación Mira Chile & \\
\hline 8. Jorge Santolalla & Perú & Percusionista. Orquesta La Única & Cumbia peruana \\
\hline 9. Widlove Dorce & Haití & Cantante. Grupo New Vision C & $\begin{array}{l}\text { Reguetón, hip-hop y } \\
\text { dancehall }\end{array}$ \\
\hline 10. Pablo Granados & Colombia & Guitarrista. Grupo Clase Latina & Vallenato \\
\hline 11. Rodolfo Downie & Panamá & $\begin{array}{l}\text { Cantante (OSO 507). Grupos Flaiter- } \\
\text { graun y The Royal González }\end{array}$ & $\begin{array}{l}\text { Rap, dancehall y } \\
\text { hip-hop }\end{array}$ \\
\hline
\end{tabular}




\begin{tabular}{|c|c|c|c|}
\hline 12. Rosa Vargas & Perú & $\begin{array}{l}\text { Bailarina y cantante. Grupos Senti- } \\
\text { miento Negro y Ébano y Marfil. }\end{array}$ & $\begin{array}{l}\text { Música criolla y } \\
\text { afroperuana }\end{array}$ \\
\hline 13. Mariela La Cruz & Perú & Bailarina. Grupo Ébano y Marfil & $\begin{array}{l}\text { Música criolla y } \\
\text { afroperuana }\end{array}$ \\
\hline 14. Juan Salvatierra & Chile & Bailarín. Grupo Ébano y Marfil & $\begin{array}{l}\text { Música criolla y } \\
\text { afroperuana }\end{array}$ \\
\hline 15. José Luis La Cruz & Perú & $\begin{array}{l}\text { Cantante, percusionista y bailarín. } \\
\text { Grupo Tres Sabores del Perú y Salsa } \\
\text { del Gran Palacio }\end{array}$ & $\begin{array}{l}\text { Música criolla, afrope- } \\
\text { ruana, cumbia y salsa }\end{array}$ \\
\hline 16. Freddy Ramírez & Perú & Bailarín. Grupo Ébano y Marfil & $\begin{array}{l}\text { Música criolla y } \\
\text { afroperuana }\end{array}$ \\
\hline 17. Analya Andrade & Chile & $\begin{array}{l}\text { Cantante, guitarrista y profesora. } \\
\text { Orquestita de la Integración }\end{array}$ & $\begin{array}{l}\text { Afroperuana, marinera } \\
\text { y cueca }\end{array}$ \\
\hline 18. Caruso Moraga & Chile & $\begin{array}{l}\text { Percusionista. Agrupación Cajone- } \\
\text { ros de Yungay (director) }\end{array}$ & $\begin{array}{l}\text { Música criolla y } \\
\text { afroperuana }\end{array}$ \\
\hline 19. Edson Darcy & Chile & Orquestita de la Integración (gestor) & \\
\hline 20. Lino Borbolla & Cuba & $\begin{array}{l}\text { Saxofonista. Grupos Cubanacán y } \\
\text { Quinteto Afro Cuba Jazz }\end{array}$ & $\begin{array}{l}\text { Música popular cubana, } \\
\text { latin jazz }\end{array}$ \\
\hline 21. Leonardo Polloni & Chile & $\begin{array}{l}\text { Encargado Oficina de Migrantes, } \\
\text { Municipalidad de Santiago }\end{array}$ & \\
\hline 22. Yonifer Celis & Colombia & $\begin{array}{l}\text { Percusionista. Grupos El Klú y Alejo } \\
\text { Vallenato }\end{array}$ & $\begin{array}{l}\text { Reguetón, hip-hop, } \\
\text { dancehall y vallenato }\end{array}$ \\
\hline $\begin{array}{l}\text { 23. Walter } \\
\text { Guadalupe }\end{array}$ & Perú & $\begin{array}{l}\text { Bailarín y percusionista. Grupos } \\
\text { Ébano y Marfil y Los Chasquis }\end{array}$ & $\begin{array}{l}\text { Música criolla y } \\
\text { afroperuana }\end{array}$ \\
\hline 24. Mayte López & Perú & $\begin{array}{l}\text { Niña de la Orquestita de la } \\
\text { Integración }\end{array}$ & Festejo y landó \\
\hline 25. Douglas Olaya & Perú & $\begin{array}{l}\text { Niño de la Orquestita de la } \\
\text { Integración }\end{array}$ & Festejo y landó \\
\hline 26. Federico Wolf & Uruguay & Cantautor y guitarrista & $\begin{array}{l}\text { Fusión (milonga, can- } \\
\text { dombe, jazz, rock y pop) }\end{array}$ \\
\hline 27. Alejandro López & Colombia & $\begin{array}{l}\text { Cantante y guitarrista. Grupo Alejo } \\
\text { Vallenato }\end{array}$ & Vallenato \\
\hline $\begin{array}{l}\text { 28. Juan Rubén } \\
\text { Berríos }\end{array}$ & Perú & $\begin{array}{l}\text { Bailarín. Grupo Perú Danza } \\
\text { (director) }\end{array}$ & $\begin{array}{l}\text { Ritmos de la costa, sierra } \\
\text { y selva peruana }\end{array}$ \\
\hline 29. Daniel Lavalle & Perú & $\begin{array}{l}\text { Cantante, percusionista y bailarín. } \\
\text { Grupos Sentimiento Negro y Daniel } \\
\text { Lavalle y tribu }\end{array}$ & $\begin{array}{l}\text { Música criolla, afrope- } \\
\text { ruana y salsa }\end{array}$ \\
\hline 30. Sammy Molano & Colombia & $\begin{array}{l}\text { Baterista y productor. Grupo Café } \\
\text { Moreno }\end{array}$ & $\begin{array}{l}\text { Música colombiana y } \\
\text { para eventos }\end{array}$ \\
\hline 31. Robert Galicia & Perú & Percusionista. Ángeles's Orquesta & $\begin{array}{l}\text { Salsa, cumbia y } \\
\text { merengue }\end{array}$ \\
\hline 32. Roxana Brínguez & Cuba & Cantante. Grupo La Timba Latina & Timba, salsa y jazz \\
\hline $\begin{array}{l}\text { 33. Carolina } \\
\text { Saavedra }\end{array}$ & Colombia & $\begin{array}{l}\text { Bailarina. Grupos La Ceiba, Café } \\
\text { Moreno y Colombia Viva }\end{array}$ & $\begin{array}{l}\text { Afrocolombiana y fol- } \\
\text { clor colombiano }\end{array}$ \\
\hline
\end{tabular}




\begin{tabular}{|c|c|c|c|}
\hline 34. Julio Blanc & Argentina & $\begin{array}{l}\text { Cantante y guitarrista. Grupos Tuti } \\
\text { Blanc (solista) y Cable a Tierra (en } \\
\text { Argentina) }\end{array}$ & Rock latinoamericano \\
\hline 35. Javiera Fuentes & Chile/Perú & $\begin{array}{l}\text { Niña de la Orquestita de la } \\
\text { Integración }\end{array}$ & Landó y marinera \\
\hline $\begin{array}{l}\text { 36. Claudio } \\
\text { Nascimento }\end{array}$ & Brasil & $\begin{array}{l}\text { Contra-Mestre en grupo Capoeira } \\
\text { Raça }\end{array}$ & Capoeira \\
\hline $\begin{array}{l}\text { 37. Alexander } \\
\text { Granados }\end{array}$ & Colombia & $\begin{array}{l}\text { Tambor, tambora y kuisi (gaita). } \\
\text { Luthier }\end{array}$ & $\begin{array}{l}\text { Música andina colom- } \\
\text { biana, vallenato, cumbia }\end{array}$ \\
\hline 38. Daniel Severín & Chile & $\begin{array}{l}\text { Integrante Academia Ritmo, Sabor } \\
\text { y Cajón }\end{array}$ & Música criolla \\
\hline 39. Gina de la $\mathrm{Hoz}$ & Colombia & $\begin{array}{l}\text { Percusionista. Grupos La Ceiba, La } \\
\text { Chilombiana y Mákina Kandela }\end{array}$ & Música costeña y fusión \\
\hline 40. Hernán Zuluaga & Colombia & Cantautor. Grupo Café Moreno & $\begin{array}{l}\text { Cancionero } \\
\text { latinoamericano }\end{array}$ \\
\hline 41. Jeison Molina & Colombia & Cantautor e instrumentista & Músicas colombianas \\
\hline 42. Wendy Lozano & Perú & Cantante & Música criolla \\
\hline 43. Luis Maldonado & Ecuador & Músico instrumentista y cantante & Música otavaleña \\
\hline $\begin{array}{l}\text { 44. Mirian } \\
\text { Maldonado }\end{array}$ & Ecuador & Cantante & Música otavaleña \\
\hline 45. Fabio Da Silva & Brasil & $\begin{array}{l}\text { Percusionista (birimbao, pandero, } \\
\text { atabaque) }\end{array}$ & $\begin{array}{l}\text { Capoeira y } \\
\text { bumba-meu-boi }\end{array}$ \\
\hline 46. Jorge Moreno & Bolivia & $\begin{array}{l}\text { Bailarín en comparsas de bailes } \\
\text { religiosos bolivianos }\end{array}$ & Tradicional andina \\
\hline
\end{tabular}

Fuente: elaboración propia. Entrevistas realizadas por el equipo de investigadores del Proyecto Fondecyt Regular № 110928, enumeradas en la tabla según orden de realización.

La observación de estas nuevas escenas musicales (Bennett y Peterson, 2004) de inmigrantes en la ciudad de Santiago, nos permitió constatar su carácter emergente y en cierta forma intersticial ya que no cuentan con circuitos permanentes de difusión ni una gran visibilidad en el espacio público. No obstante, nos fue posible identificar ciertas redes de músicos, mediadores y lugares habituales de encuentro que, a pesar de su carácter fragmentario y esporádico, organizan periódicamente actividades, hacen circular repertorios e interpelan a un cierto tipo de público.

En el siguiente apartado, abordaremos la cuestión de la configuración de identidades en los músicos, poniendo especial énfasis en los imaginarios artísticos vehiculados en cada una de las trayectorias analizadas. Para ello, presentaremos distintas modalidades en que se declinan estas identidades conforme a imaginarios de nación, de etnia, de géneros musicales o de ciertas figuras del artista. 


\section{IDENTIDADES NACIONALES}

Se trata de una identidad presente mayoritariamente en los músicos que ejecutan repertorios de música tradicional popular, que se constituye a partir de la identificación con géneros y ritmos asociados a una cultura musical nacional (Martí, 2004).

Un ejemplo de ella es la que hemos reconocido como la escena musical peruana (Facuse y Torres, 2017; Cayupi, 2017), formada por un grupo de músicos asentados en nuestro país desde la década de los noventa provenientes de Lima, quienes se han dedicado a interpretar repertorios de música criolla y afroperuana. En este grupo, la noción de "embajadores culturales" cobra pleno sentido toda vez que muchos de ellos han asumido la tarea de difundir en la diáspora la cultura peruana en diversos escenarios (Día del Perú, circuito de restaurantes de la capital y festivales), así como también a un trabajo de transmisión a través de la creación de academias y talleres de música y danza en los que participa un público de chilenos e inmigrantes de distintos lugares del continente. Estos artistas suman a estas estrategias de divulgación de sus músicas tradicionales, otro tipo de mediaciones tales como programas de radio, redes sociales o comercialización de sus discos. También, muchos de ellos se presentan en espacios de representación institucional, como embajadas y consulados, a través de espectáculos musicales para la comunidad residente y las autoridades diplomáticas.

La referencia a identidades e imaginarios nacionales es así encarnada por estos músicos y su interpretación de repertorios emblemáticos de sus respectivos países. Entre los entrevistados encontramos trayectorias como la de Angélica Altamirano o Martín Zegarra, ambos peruanos, intérpretes de música criolla que desde hace años forman parte de este tipo de circuitos.

Esta dimensión nacional de la producción cultural cobra sentido también para el turismo como forma de renovar la imagen de estos países en el mundo en el contexto de la globalización. Ejemplo de ello son actividades como Perú Gourmet ${ }^{3}$, evento anual organizado por la red de empresarios gastronómicos peruanos en Santiago, o Noches del Mundo, realizada en un lujoso distrito de la capital donde se presentó el espectáculo Colombia es Pasión promocionado por Colombia ProExport ${ }^{4}$. Este tipo de eventos se convierten en plataformas de una nueva manera de escenificar imaginarios nacionales en las cuales la música y el baile juegan un rol preponderante, tal como lo expresa un músico colombiano haciendo referencia al Ballet Colombia Viva: "ProExport nos tomó y trabajamos mucho con ellos en los showrooms de turismo; fuimos imagen de Colombia es Pasión en Chile" (H. Zuluaga, cantautor colombiano, entrevista personal, 2014).

Estas identidades nacionales escenificadas en distintos contextos se van complejizando a partir del cruce con otras culturas musicales locales, étnicas o transnacionales. Lo nacional como territorio imaginario opera como una base desde la cual comienzan a superponerse otras pertenencias e

3 Perú Gourmet es un evento anual orientado a visibilizar el aporte de la comunidad peruana residente en Chile desde la gastronomía. Fue creado en 2012 para la realización del Primer Festival de Gastronomía Peruana en Chile. Está asociado a otros eventos como "El Día del Ceviche", "La Noche del Pisco", "Fronteras" y "Perú Celebra".

4 Colombia ProExport es parte de ProColombia, entidad colombiana orientada a la promoción del turismo y la inversión extranjera en el país. 
identificaciones. Es así como muchos de los músicos entrevistados se identifican fuertemente con sus barrios o pueblos de origen (la Victoria en Lima, el puerto del Callao o Chincha para el caso peruano) o con identidades urbanas o regionales (la sierra y la costa en Perú, Bogotá o Medellín en Colombia, Otavalo o Guayaquil en Ecuador, entre otras). Las identidades nacionales en que se reconocen estos músicos no son homogéneas sino que cubren pertenencias mucho más específicas, cada una de las cuales posee su propia densidad de significaciones que se despliegan a través de prácticas musicales y dancísticas particulares.

Lo nacional opera en consecuencia como primera estrategia de presentación, desde donde los músicos transitan hacia otras escenas y estilos musicales. Un ejemplo de ello es el grupo "Tres Sabores del Perú", quienes han ido ampliando su repertorio de acuerdo a los diferentes públicos latinoamericanos que los "recepcionan", tocando bolero y son cubano, cueca chilena, cumbia colombiana, zamba y tango argentino o incluso, adaptándose a los repertorios regionales existentes al interior de Perú (vals limeño, de Trujillo, o música andina).

Podemos así hablar de una identidad nacional que lejos de permanecer fija se diversifica de acuerdo a las trayectorias de los músicos, sus grupos y de los públicos a los que se confrontan, modulando con flexibilidad y creatividad la integración de nuevos elementos al trabajo musical. Esta diversificación permite igualmente la conformación de comunidades musicales que se reúnen, ya no solamente en torno a la idea de nación, sino que se abren al encuentro con nuevos repertorios culturales en el espacio transnacional.

\section{IDENTIDADES ÉTNICO-RELIGIOSAS}

Una segunda dimensión en que se declinan las identidades de las comunidades diaspóricas en Chile, se relaciona con las pertenencias étnicas y religiosas en torno a las cuales se ponen en escena distintas ritualidades en el espacio público. Estas manifestaciones permiten a la vez, restituir un vínculo con el lugar de origen y dar visibilidad a estas colectividades en el nuevo contexto de acogida. De manera paralela a lo que hemos reconocido como identidades nacionales, algunas comunidades como las andinas o las afrodescendientes, comparten elementos que, en su conjunto, remiten a entramados socioculturales específicos, en los que la música y la danza son un importante recurso para dar continuidad y reconfigurar sus identidades. Al mismo tiempo, estas prácticas permiten establecer diálogos con la población local que participa de las actividades, creando un terreno común a partir de un conjunto de formas artísticas, rituales y festivas que parecieran converger hacia una política del reconocimiento.

En las comunidades provenientes de nuestros países vecinos, Perú y Bolivia, ocupan un lugar relevante algunas prácticas rituales y religiosas asociadas a figuras de la devoción popular. Organizados como hermandades o comparsas, estos grupos celebran diversas vírgenes y santos, carnavales y otras festividades a través de procesiones en las que convergen múltiples manifestaciones musicales y dancísticas de tradición andina (caporales, morenadas, saqras, qhapaq qollas, qhapaq chunchos, qhapaq negros, majeños, contradanza y otras), las que han comenzado a marcar nuevos hitos en el 
Tabla 3. Fiestas religiosas de inmigrantes en la Región Metropolitana de Santiago

\begin{tabular}{lll}
\hline Nombre de la deidad & Lugar de origen & Fecha de la festividad \\
\hline Virgen de Chapi & Chapi, Arequipa, Perú & 1 de mayo \\
\hline Virgen del Carmen & Paucartambo, Cusco, Perú & 16 de julio \\
\hline Virgen de Copacabana & Copacabana, Bolivia & 5 de agosto \\
\hline Virgen de Urkupiña & Quillacollo, Bolivia & 15 de agosto \\
\hline Santa Rosa de Lima & Lima, Perú & 30 de agosto \\
\hline Señor de los Milagros & Lima, Perú & Mes de octubre \\
\hline San Martín de Porres & Lima, Perú & 3 de noviembre \\
\hline Virgen de Cotoca & Cotoca, Santa Cruz, Bolivia & 8 de diciembre \\
\hline Virgen de la Puerta & Otuzco, Trujillo, Perú & 13 al 16 de diciembre \\
\hline
\end{tabular}

Fuente: elaboración propia. Equipo del Proyecto Fondecyt Regular № 110928.

calendario religioso popular y sus escenificaciones en la ciudad (ver Tabla 3).

Estas prácticas festivo-religiosas realizadas por comunidades culturalmente adscritas al mundo andino ${ }^{5}$, son de particular interés por los procesos de interacción cultural en los que se proyectan y actualizan elementos de cosmovisiones americanas prehispánicas. Ellas se dan en concomitancia con una emergente consciencia de la "andinidad" histórica de la ciudad capital de Chile, que se manifiesta en diversas expresiones locales impulsadas por una extensa red de jóvenes citadinos que proponen una valoración y reconexión con el mundo andino en particular, y con los pueblos originarios en general (Figura 1).

En el contexto de estas prácticas musicales, la figura individual de los músicos pierde relevancia para subsumirse en el colectivo. Los músicos y bailarines entrevistados, más

5 En el ámbito de la antropología y arqueología, lo que aquí consignamos como mundo andino se ha conceptualizado como área cultural andina, que geográficamente abarca territorios de Ecuador, Perú Bolivia, Argentina y Chile. que darle relevancia a sus modos de aprendizaje o a la especificidad de un oficio, destacan el sentido fundamentalmente religioso que da sustento a su práctica. Música y danza se convierten aquí en una forma de plegaria, mediación entre una comunidad y su espacio sagrado y ritual.

La convergencia recurrente de estas prácticas devocionales en ciertos territorios de la ciudad, ha implicado una resignificación de aquello que algunos autores han reconocido como "territorios de frontera física y simbólica” (Márquez, 2014, p. 50). Ejemplo de ello es el circuito de calles en el centro de Santiago, que marcan los recorridos consuetudinarios de pasacalles devocionales y de celebraciones litúrgicas, las que tienen como ejes de referencia los principales templos católicos, como la Catedral en la Plaza de Armas, la Iglesia Santo Domingo, la Iglesia Recoleta San Francisco y la Parroquia Latinoamericana en el Parque Bustamante.

La presencia de estas comunidades en espacios públicos de la ciudad, con sus particulares maneras de escenificar la devoción 


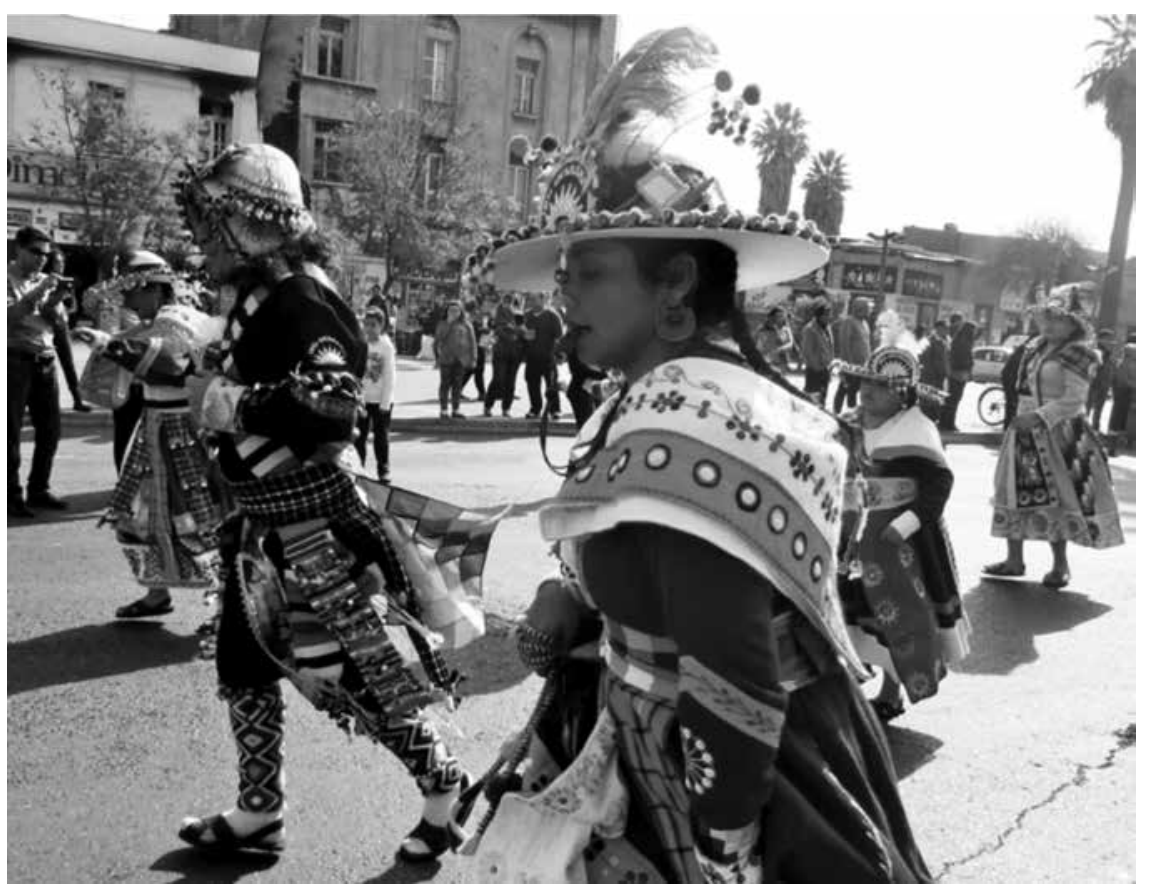

Figura 1. Comparsa boliviana en procesión de la Virgen de Copacabana en el centro de Santiago de Chile Fuente: Marisol Facuse (1 de agosto de 2015). Archivo de imágenes Proyecto Fondecyt Regular № 110928.

popular a través de la música y la danza, traspasa las barreras nacionales y su historia de conflictos geopolíticos, logrando generar un dispositivo que podríamos calificar como transnacional o translocal, en tanto conecta el acá y el allá territorial, social y cultural de estas comunidades migrantes en nuestro país.

La música y la danza no solo se convierten en dispositivo de puesta en valor de estas identidades étnicas y religiosas, sino que permiten establecer diálogos y alianzas estratégicas con instituciones y agrupaciones locales. De este modo y para garantizar la realización de estas festividades, estas hermandades han integrado a jóvenes músicos y danzantes chilenos. Estos grupos, sin perder su identidad étnica, pueden negociar una cierta idea de autenticidad con el fin de mantener la ritualidad y su temporalidad como marca necesaria para la preservación de una identidad en la diáspora.

\section{IDENTIDADES PROFESIONALES}

Esta tercera manera de mostrar las identidades se refiere al lugar de estos músicos respecto a los mundos musicales en los que se habilitan profesionalmente: ¿Dónde se sitúa su actividad musical? ¿En qué espacio territorial y social? ¿Buscando llegar a qué públicos? ¿Con qué otros mundos del arte interactúan estos músicos? Asimismo, nos 
interesamos por saber si se trata de una actividad remunerada o no, si se ejerce en paralelo con otros oficios alejados del dominio artístico, sus niveles de profesionalización, las marcas de reconocimiento por circuitos nacionales o internacionales, los etiquetajes de los que son objeto y sus relaciones con la industria y el mercado.

En los músicos entrevistados, estos procesos de profesionalización y de consolidación de una carrera artística, suelen estar dados por diversos aspectos: el tipo de formación, la regularidad de la práctica o los circuitos musicales en los que se participa, el reconocimiento por parte de sus pares, tanto en Chile como en sus países de origen, o la generación de ingresos a través de la práctica musical.

Encontramos así, una diversidad de posibilidades y posicionamientos de los músicos respecto a una cierta idea del artista profesional. Algunos de ellos son solistas o participan de uno o más grupos musicales formados por inmigrantes o nativos. En cualquiera de estos casos, la mayoría de los músicos explora más de un género musical de manera paralela (música criolla, afroperuana y salsa; música criolla, bolero y mariachi; chicha y balada romántica, etc.), o a lo largo de su trayectoria, pudiendo incluso incursionar en otras prácticas artísticas tales como la danza, el teatro o el cuentacuentos, lo que en este estudio hemos reconocido como prácticas artísticas asociadas a la música.

Un ejemplo que ilustra de manera nítida la cuestión de los diferentes caminos hacia una profesionalización, lo encontramos en las trayectorias de Hernán Zuluaga y Sammy Molano, dos músicos originarios de Medellín. Hernán se formó en la interpretación de músicas colombianas tradicionales para luego ir abriéndose a otros géneros musicales. Sammy, por su parte, se inició como baterista autodidacta a muy temprana edad, participando en ambientes rockeros y desde los doce años comenzó a trabajar profesionalmente, tocando junto a otros músicos repertorios de naturaleza diversa.

Ambos se encuentran en el medio musical de Medellín y en distintos momentos de sus biografías, deciden emigrar a Santiago donde se reencontraron y formaron el grupo Café Moreno en el año 2003 como estrategia de inserción en el medio local, interpretando variados repertorios bailables para un público predominantemente chileno. Al momento de la entrevista, ambos estaban tomando opciones musicales distintas. Sammy decidió continuar tocando música bailable especialmente en matrimonios y fiestas, lo que le reportaba una cantidad considerable de ingresos aunque no una gran realización desde el punto de vista artístico. Hernán, en cambio, tomó la opción de dedicarse a la cantautoría y a la interpretación de repertorios de la trova latinoamericana y española, que había sido su género predilecto desde su época en Medellín, privilegiando bares o cafés como espacio de escenificación. Si bien esta opción no le garantiza una gran estabilidad económica, se aproxima mucho más a su ideal de artista cercano al imaginario del trovador, que pone en el centro un contacto más íntimo con sus públicos y la necesidad de contar historias a través de las canciones. Desde hace años pertenece a una red de cantautores de Colombia llamada Fundación Barrio Colombia que organiza el Festival Internacional de la Canción Itinerante (FICIB). 
Esta bifurcación de carreras de artistas con un origen común, cobra gran interés para un análisis del impacto del fenómeno migratorio en las trayectorias de los músicos. En la actualidad, Hernán se reivindica en tanto artista como intérprete y cantautor. Sammy, por su parte, se ha orientado hacia una profesionalización optando por circuitos más comerciales relacionados con la gestión de eventos (matrimonios, fiestas familiares, días nacionales), lo que se traduce en la elección de géneros musicales destinados a un público más amplio.

En nuestro análisis, ambos vienen a encarnar dos figuras de artista ancladas en imaginarios distintos que conducen a dos formas de profesionalización. Una, tributaria de un imaginario del artista bohemio, que elige el bar como escena de sus espectáculos poniendo como principio el valor poético, introspectivo y biográfico de la canción y una relación cercana con el público. El otro, encarna una idea más funcional del músico, también asociado a la noche, pero en donde predominan los valores de la fiesta, del baile y de la entretención así como la búsqueda de una carrera de músico exitosa y estable, desarrollando de manera paralela otra carrera como productor, lo que nos permite situarlo en la figura del músico como empresario de sí mismo.

En otros de los casos analizados, la práctica musical se distancia de la búsqueda de una realización artística para jugar un rol auxiliar, que permite poner en relevancia una singularidad que exacerba una diferencia, como ocurre con peruanos y otavaleños, que comercializan sus productos artesanales y culinarios en ferias y mercados. Es así, que podemos hablar de una práctica musical estratégica, coadyuvante de otras prácticas en el espacio público en el contexto migratorio. Es el caso de Wendy Lozano, cantante peruana aficionada y comerciante ambulante, quien vende café, helados, comida preparada y ropas en el Mercado Central de Santiago. Su país de origen y sus canciones le permiten la construcción de un personaje que sus clientes identifican como "la peruanita que canta", lo que parece marcar la venta de sus productos con un sello identitario particular y una plena integración a ese lugar, que reconoce como su segundo hogar.

\section{IDENTIDADES MESTIZAS}

Como hemos visto en los ejes de las identidades hasta aquí analizadas, estas pueden declinarse de manera distinta a partir de la pertenencia a un territorio, a un imaginario nacional o étnico o a un determinado género o estilo musical. Es a partir de esta última dimensión, desde donde hemos observado un tipo de identidad que reconocemos como mestiza, en el sentido que hemos referido más arriba y que se expresa centralmente en un modo de hacer música. Se trata, en consecuencia, de identidades eminentemente musicales que se van esculpiendo, tanto en trayectorias de artistas como en el modo de organización del trabajo creativo y en las poéticas que sustentan su propuesta. En estos casos, se privilegia la búsqueda de una sonoridad en las antípodas del purismo nacional o de una idea de origen, en favor de la mezcla, la fusión y la experimentación.

Un ejemplo de este tipo de identidad lo encontramos en agrupaciones como La Chilombiana y Mákina Kandela, en las que participó Gina De La Hoz, percusionista que reside en Chile desde el año 2008, cuya 
trayectoria musical ha tenido a la tambora como instrumento principal, un tambor tradicional de la música de la costa atlántica de Colombia. Originaria de Bogotá, Gina realizó estudios universitarios en relaciones internacionales y gestión social, desarrollando de manera paralela una carrera musical. Durante este período, formó parte de la agrupación bogotana La Comparsa de los Músi$\cos$ (2005), que participaba año tras año en el Carnaval de Bogotá y realizó giras nacionales e internacionales. En este contexto llegó a Chile, donde se incorporó a los circuitos de música urbana en Valparaíso y Santiago, integrando y fundando los grupos Bareke, La Chilombiana, La Ceiba y Mákina Kandela. Todas estas agrupaciones tenían como base de sus propuestas a la música costeña colombiana, particularmente la de tambores y gaitas y la cumbia, fusionadas en grados diversos con otros elementos o estilos. Estas propuestas musicales interactuaron con el movimiento de jóvenes músicos conocido como "Nueva Cumbia Chilena", de gran impacto en la renovación de la música tropical en el país, en la que destacan grupos como Chico Trujillo (1999), Banda Conmoción (2001), La Mano Ajena (2002), Juana Fe (2003), Combo Ginebra (2004), Anarkia Tropikal (2005), Chorizo Salvaje (2006) y Villa Cariño (2008) entre otros.

Refiriéndose a su participación en La Chilombiana (2008), Gina señala: "Hacíamos música fusión con rock, jazz, con varios tintes, pero siempre teniendo como base la timbrística de instrumentos colombianos como tambora, maracas, platillos, guache y tambor alegre" (G. De la Hoz, percusionista colombiana, entrevista personal, 2014).

El origen plurinacional de sus integrantes, vinculados por sus trayectorias a Colombia,
Perú, Ecuador y Chile, se expresa en el comentario de Tocori Berrú, fundador del grupo, sobre esta tendencia a la mixtura de este colectivo musical: "Chilombiana es un concepto musical, cultural y mestizo" (Ponce, s. f.).

El grupo La Ceiba, por otra parte, integrado por músicos colombianos y chilenos, cultivó también un repertorio anclado en la música costeña y desde ahí fue abriéndose hacia el rock. Este grupo fue la base de un nuevo proyecto musical del cual Gina forma parte hasta hoy, Mákina Kandela (2010), colectivo de músicos que radicalizó el afán experimental de fusionar músicas locales latinoamericanas (colombianas y otras) con músicas urbanas contemporáneas. Esta agrupación se distingue por explorar con mayor profundidad el sonido tradicional de las gaitas y las percusiones costeñas colombianas desde una poética composicional innovadora, propiciadora de mixturas sin fronteras locales y que ha decantado en un sello sonoro propio.

En todas las agrupaciones en las que ha participado, Gina ha desempeñado de manera paralela importantes labores de producción cultural gracias a lo cual los grupos han financiado giras, presentaciones y edición de discos. En este contexto, esta artista ha demostrado una gran capacidad de gestión de proyectos musicales en un espacio transnacional, estableciendo conexiones con la escena musical bogotana asociada el movimiento conocido como Nueva Música Colombiana (Santamaría, 2007). Son emblemáticos de este movimiento músicos y grupos de Bogotá, Medellín y Cali principalmente, como Meridian Brothers (1998), Puerto Candelaria (2000), Curupira (2000), ChocQuibTown (2000), La Mojarra Eléctrica 
(2001), La Revuelta (2002), Bomba Estéreo (2006) y Systema Solar (2006), entre otros.

La trayectoria de Gina, así como la del grupo Mákina Kandela, está conectada con un circuito en el que coparticipan músicos de Colombia, Chile, Argentina y Brasil. Esto ejemplifica la actual dinámica de interconexión latinoamericana entre distintas escenas urbanas en torno a la cual se han ido generando plataformas de producción y circulación de músicos independientes, basados en la autogestión y en la creación de redes musicales translocales. $\mathrm{Al}$ respecto, mencionamos el caso de sellos grabadores independientes generados por los propios músicos: La Distritofónica (Bogotá), Merlín Producciones (Medellín) y La Makinita (Santiago).

Es de interés para nuestro estudio, constatar la simultaneidad de estos procesos de mestizaje musical en dos territorios distantes como son Chile y Colombia, que parecen dar cuenta de una búsqueda de los músicos de inicios del siglo XXI por revisitar las músicas urbanas, populares y tradicionales a partir de estrategias creativas e innovadoras, que se sirven tanto de medios virtuales como presenciales. Las migraciones musicales pueden así ser pensadas en nuevos términos, a partir del desplazamiento de músicos latinoamericanos por el territorio, quienes devienen en agentes que posibilitan el intercambio, la creación de circuitos y plataformas, generando nuevos espacios de diálogo musical y cultural.

\section{Conclusiones}

Como hemos visto, las nuevas inmigraciones que han tenido lugar en las últimas décadas en Chile, han repercutido progresivamente en las dinámicas culturales provocando encuentros y cruces a partir de las prácticas musicales, rituales y festivas en el espacio urbano.

Si volvemos a las preguntas planteadas al inicio de este artículo, podemos constatar que efectivamente las prácticas musicales de los inmigrantes latinoamericanos posibilitan la creación de vínculos sociales inéditos, tanto al interior de sus comunidades nacionales como entre inmigrantes y población nativa, y también, entre inmigrantes de distintas procedencias. Las trayectorias musicales, los tipos de identidad y las actividades en torno a las cuales se reúnen estas comunidades, dan cuenta de múltiples formas de mestizaje cultural producido a distintas escalas entre quienes participan de una manera $u$ otra de estas escenas musicales.

Asimismo, hemos visto que estos procesos de mestizaje cultural pueden atravesar distintos dominios: étnico, nacional, musical o imaginario. Ello se hace manifiesto en las distintas formas en que se declinan y se combinan las identidades de los músicos. En el caso de aquellas identidades que hemos reconocido como mestizas, se hacen evidentes los cruces y la creación de nuevas dinámicas colectivas generadas por los propios músicos, a partir de búsquedas de estéticas y referentes que traspasan las fronteras tradicionales establecidas por los géneros musicales o las identidades nacionales.

La observación durante un largo período de las músicas inmigrantes latinoamericanas, nos permitió constatar que se trata de un mundo del arte emergente, estructurado a partir de redes heterogéneas, en donde suele primar una organización de tipo autogestionaria. Asimismo, no existen aún circuitos consolidados de distribución, ni altos 
grados de institucionalización promovidos por las políticas culturales.

Los actores en torno a los que se articulan estas identidades en la diáspora son múltiples; ya no es monopolio únicamente de los Estados proyectar una imagen de los países en el mundo sino que se han ido introduciendo con fuerza otros actores en el contexto de la globalización cultural. Un ejemplo importante, como hemos visto, son los empresarios del turismo y la gastronomía, gestores de actividades y promotores de circuitos en los que la música y la danza operan como coadyuvantes de una cierta puesta en escena de la identidad nacional. Otros actores relevantes son las propias comunidades nacionales migrantes organizadas, quienes a otra escala gestionan circuitos y formas de existir socialmente en el país de acogida. La música adquiere aquí un rol preponderante, cuyo impacto puede llegar a distintas comunidades y territorios a través de la organización autogestionada de actividades (talleres populares, muestras y ferias), donde tienen primacía valores como el mutuo reconocimiento, la solidaridad y la interculturalidad.

Especial relevancia cobra aquí el trabajo creativo de una nueva generación de músicos chilenos que comienzan a circular e interactuar en un diálogo más cercano y fluido con sus pares musicales de distintos países de la región, lo que nos permite pronosticar que asistimos a un punto de inflexión importante en la vida musical de nuestro país. Estas transformaciones parecen operar a la vez en continuidad y en ruptura con un proceso de más larga duración, en el que Chile ha ido reelaborando su pertenencia al territorio cultural y simbólico de América
Latina. Nos alejamos de una construcción de una Latinoamérica mediada por la literatura, el cine o los movimientos musicales (nueva canción) de los años sesenta, para comenzar a conectarnos directamente con las biografías, las prácticas musicales y las formas culturales encarnadas en los trayectos de la migración latinoamericana.

\section{REFERENCIAS}

Amselle, J. (2010). Logiques métisses. Anthropologie de l'identité en Afrique et ailleurs. París, Francia: Payot.

Arriagada, C., y Órdenes, S. (2011). Inmigrantes internacionales, ciudad y servicios sociales urbanos: el desafío de la integración con diversidad. Santiago de Chile, Chile: Editorial Universidad de Chile.

Becker, H. (2008). Los mundos del arte. Buenos Aires, Argentina: Editorial Universidad Nacional de Quilmes.

Becker, H. (2009). Outsiders: hacia una sociología de la desviación. Buenos Aires, Argentina: Siglo Veintiuno Editores.

Bennett, A., y Peterson, R. (2004). Music Scenes. Local, Translocal, and Virtual. Nashville, TN: Vanderbilt University Press.

Burke, P. (2013). Hibridismo cultural. Madrid, España: Akal.

Caba, S., y Rojas, M. (2014). Patrimonio migrante. Construcción social e inclusiva identitaria de la comunidad peruana en Santiago de Chile. Estudios Avanzados, (22), 86-115. Recuperado de http:// www.revistas.usach.cl/ojs/index.php/ ideas/article/view/1878

Cayupi, M. (2017). Construcción de la 'peruanidad' en la escena de música criolla y afroperuana en Santiago de Chile (tesis de 
pregrado). Universidad de Chile, Santiago, Chile.

Cluley, R. (2012). Art Words and Art Worlds:

The Methodological Importance of Language Use in Howard S. Becker's Sociology of Art and Cultural Production. Cultural Sociology, 6(2), 201-216. DOI: https://doi.org/10.1177/1749975512440223 Recuperado de http://citeseerx.ist.psu. edu/viewdoc/download?doi=10.1.1.93 5.4650\&rep $=$ rep $1 \&$ type $=$ pdf

DeNora, T. (2004). Music in Everyday Life. Cambridge, Reino Unido: Cambridge University Press.

Dutheil-Pessin, C. (2004). La chanson réaliste. Sociologie d'un genre. París, Francia: L'Harmattan.

Duvignaud, J. (1981). Sociología del teatro: ensayo sobre las sombras colectivas. México D. F., México: Fondo de Cultura Económica.

Esquenazi, J. (2007). Sociologie des oeuvres. De la production à l'interprétation. París, Francia: Armand Colin.

Facuse, M., y Torres, R. (2017). Músicas inmigrantes latinoamericanas en Santiago de Chile: el caso de la escena musical peruana. Revista Musical Chilena, 71(227), 11-47. DOI: http://dx.doi. org/10.4067/s0716-27902017000100011 Recuperado de https://scielo.conicyt. cl/pdf/rmusic/v71n227/0716-2790-rmusic-71-227-0011.pdf

Geertz, C. (2000). La interpretación de las culturas. Barcelona, España: Gedisa.

Gruzinski, S. (2000). El pensamiento mestizo. Barcelona, España: Paidós Ibérica.

Hennion, A. (2002). La pasión musical. Barcelona, España: Paidós Ibérica.

Imilan, W. (2014). Restaurantes peruanos en Santiago de Chile: construcción de un paisaje de la migración. Revista de
Estudios Sociales, (48), 15-28. Recuperado de http://www.redalyc.org/articulo. oa? id=81530018002

Imilan, W. y Millaleo, A. (2015). Comer a lo peruano. Lugares de la migración gastronómica. En W. Imilan et al. (Eds.), Rutas migrantes en Chile. Habitar, festejar y trabajar. Santiago de Chile, Chile: Ediciones Universidad Alberto Hurtado.

Jaramillo, J. (2006). Frecuencias temáticas de la historiografía latinoamericana. En L. Zea (Coord.), América Latina en sus ideas (pp. 23-45). México, D. F., México: Siglo Veintiuno Editores.

Kaufmann, J. (2011). L'entretien compréhensif. París, Francia: Armand Colin.

Lapassade, G. (1996). Les microsociologies. París, Francia: Anthropos.

Laplantine, F., y Nouss, A. (2007). Mestizajes: de Arcimboldo a Zombi. Buenos Aires, Argentina: Fondo de Cultura Económica.

Laplantine, F., y Nouss, A. (2008). Le métissage. París, Francia: Téraèdre.

Márquez, F. (2014). Inmigrantes en territorios de frontera. La ciudad de los otros. Santiago de Chile. EURE - Revista de Estudios Urbano Regionales, 40(120), 49-72. DOI: http://dx.doi.org/10.4067/S025071612014000200003 Recuperado de https://scielo.conicyt.cl/scielo.php?pi$\mathrm{d}=$ S0250-71612014000200003\&script=sci_arttext

Márquez, F., y Correa, J. (2015). Identidades, arraigos y soberanías. Migración peruana en Santiago de Chile. Polis, 14(42), 167-189. DOI: http://dx.doi.org/10.4067/ S0718-65682015000300009 Recuperado de https://journals.openedition.org/po lis/11316

Martí, J. (2004). Transculturación, globalización y músicas de hoy. TRANS 
- Revista transcultural de música, (8), 0 . Recuperado de http://www.sibetrans. com/ trans/articulo/188/transcultura cion- globalizacion-y-musicas-de-hoy

Olmos, M. (2012). Antropología de la migración musical. En M. Olmos (Coord.), Músicas migrantes: la movilidad artística en la era global. Tijuana, México: El Colegio de la Frontera Norte.

Péquignot, B. (2007). La question des oeuvres en sociologie des arts et de la culture. París, Francia: L'Harmattan.

Ponce, D. (s. f.). Chilombiana (MusicaPopular.cl. La enciclopedia de la música chilena). Recuperado de http://www. musicapopular.cl/grupo/chilombiana/

Santamaría, C. (2007). La Nueva Música Colombiana. La redefinición de lo nacional en épocas de la world music. El Artista. Revista de Investigaciones en Música y Artes Plásticas, (4), 6-24. Recuperado de http://www.redalyc.org/ pdf/874/87400402.pdf

Silverman, D. (2011). Interpreting qualitative data: A guide to the principles of qualitative research. Londres, Reino Unido: Sage.
Stefoni, C. (Ed.) (2011). Mujeres inmigrantes en Chile. ¿Mano de obra o trabajadoras con derechos? Santiago de Chile, Chile: Ediciones Universidad Alberto Hurtado.

Stefoni, C., y Bonhomme, M. (2015). Vidas que se tejen en contextos transnacionales. Un recorrido por el trabajo, la familia y las redes sociales. En W. Imilan et al. (Eds.), Rutas migrantes en Chile. Habitar, festejar y trabajar. Santiago de Chile, Chile: Ediciones Universidad Alberto Hurtado.

Thayer, L. (2011). Discriminación y lucha por el reconocimiento. Chilenos frente a inmigrantes en la Región Metropolitana. Ponencia presentada en el XXVIII Congreso de la Asociación Latinoamericana de Sociología - ALAS, Recife, Brasil. Recuperado de http://www.academia. edu/1090847/Discriminacion_y_lucha_ por_el_reconocimiento_chilenos_frente_a_inmigrantes_en_la_Region_Metropolitana

Tijoux, M. (Ed.) (2016). Racismo en Chile. La piel como marca de la inmigración. Santiago de Chile, Chile: Editorial Universitaria. 